\title{
Improving Energy Poverty Measurement in Southern European Regions through Equivalization of Modeled Energy Costs
}

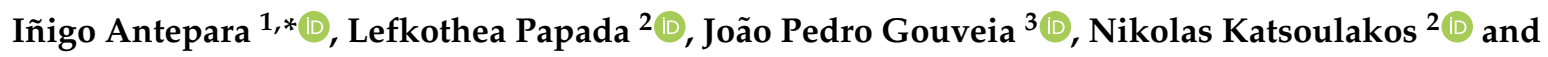 \\ Dimitris Kaliampakos ${ }^{4}$ \\ 1 Alokabide, Technical Department, Portal de Gamarra, 1A-2a planta (Edificio el Boulevard), \\ 01013 Vitoria-Gasteiz, Spain \\ 2 Metsovion Interdisciplinary Research Center, National Technical University of Athens, \\ 9 Heroon Polytechneiou Str., Zographos, 15780 Athens, Greece; lefkipap@metal.ntua.gr (L.P.); \\ katsoulakos@metal.ntua.gr (N.K.) \\ 3 CENSE Center for Environmental and Sustainability Research, NOVA School of Science and Technology, \\ NOVA University Lisbon, 2829-516 Caparica, Portugal; jplg@fct.unl.pt \\ 4 School of Mining and Metallurgical Engineering, National Technical University of Athens, \\ 9 Heroon Polytechneiou Str., Zographos, 15780 Athens, Greece; dkal@central.ntua.gr \\ * Correspondence: i.antepara@alokabide.eus; Tel.: +34-945-000-565
}

Received: 21 June 2020; Accepted: 14 July 2020; Published: 16 July 2020

\begin{abstract}
In many European countries, energy poverty is measured on the basis of real energy bills, as theoretical energy costs are hard to calculate. The UK is an exception-the data inputs for the Low Income-High Cost (LIHC) indicator are based on reasonable energy costs, these data are collected through specially designed surveys, often an intensive and costly procedure. Approaches which calculate energy needs are valid when energy bill data are unreliable or where households restrict consumption. In this analysis, energy poverty levels are evaluated for Greece, the municipality of Évora (Portugal), and the Basque Country (Spain): energy bills are modeled based on building energy performance data and other energy uses, and adjusted according to socio-demographic variables. To this end, equivalization weights are calculated using socio-economic data from the aforementioned southern European countries/regions. Data are analyzed to compare measurements with actual versus modeled bills using the Ten-Percent Rule (TPR) and Hidden Energy Poverty (HEP) against twice the median (2M) indicator, enhancing the identification of households with low energy consumption. In conclusion, theoretical energy needs can be combined with socio-demographic data instead of actual energy bills to measure energy poverty in a simplified way, avoiding the problem of targeting households that under consume.
\end{abstract}

Keywords: energy poverty; modeled energy costs; TPR; HEP; equivalization coefficients; under consumption; Greece; Portugal; Spain

\section{Introduction}

Between 54 and 141 million people are unable to keep their homes adequately warm in Europe; these citizens are therefore considered to be in energy poverty [1]. Day et al. [2] define energy poverty as "insufficient access to affordable, reliable and safe energy services".

The European Commission (EC) is aware of the situation within many European households. In 2016, The EC published the Winter Package, which aimed to shape the clean energy transition, whilst avoiding the marginalization of vulnerable consumers. The second of eight legislative acts approved in 2019 was the European Parliament legislative resolution of 13 November 2018 on the 
proposal for a directive of the European Parliament and of the Council amending Directive 2012/27/EU on energy efficiency, which states that "the Union's energy efficiency policies should be inclusive and should therefore ensure accessibility to energy efficiency measures for consumers affected by energy poverty".

The EU Energy Poverty Observatory (EPOV) [3] initiative was launched by the EC to assist Member States (MS) in their efforts to mitigate energy poverty. One of its tasks is to define useful indicators to track the energy poverty situation across Europe. The common indicators proposed by the EPOV are [3]:

- Arrears on utility bills, share of (sub-) population having arrears on utility bills, based on self-reported experiences of limited access to energy services (i.e., EU-Statistics on Income and Living Conditions (SILC) data);

- Low absolute energy expenditure (M/2), share of households whose absolute energy expenditure is below half the national median, based on household income and/or energy expenditure data (i.e., Housing Budget Survey (HBS) data);

- High share of energy expenditure in income (2M), proportion of households whose share of energy expenditure in income is more than twice the national median share, based on HBS data;

- Inability to keep home adequately warm, share of (sub)population not able to keep their home adequately warm, based on EU-SILC data.

As acknowledged by previous research [4-6], measuring and monitoring energy poverty is challenging. The multidimensionality of the condition means that it is not captured through a single indicator, and there is also a lack of relevant and detailed key data that could be used for cross-country comparisons and for detailed regional analysis.

The first attempt to measure energy poverty was applied in the UK, using the Boardman [7] methodology. This method, known as the Ten-Percent Rule (TPR), calculates the ratio between income and energy costs, where energy costs should not exceed 10\% of household income. Energy costs are modeled rather than based on actual bills, and include space heating, domestic hot water (DHW), cooking, lighting, and additional electric appliances [8]. Critics of the method questioned the means of calculating energy costs [6] and identified an underrepresentation of the impact of other variables, such as the improvement of energy efficiency [9]. Additionally, Boardman's 10\% approach was designed for the UK, so its relevance may vary between different countries and income levels [6].

In 2012, the UK revised the definition and adopted the methodology developed by Hills [9], known as the Low Income-High Cost (LIHC), based on reasonable energy costs. Hills considered two additional criteria to measure energy poverty [10]: to identify low-income households living in inefficient dwellings as fuel-poor, and a self-reported, subjective index. Hills [9] finally recommended the energy poverty indicator was based on reasonable energy costs, and in doing so, the LIHC is regarded as a benchmark for 'objective' expenditure- and income-based indicators [11]. The main point is that energy poverty centers on a lack of sufficient warmth and space heating [12], arguably the most important domestic energy service, as a consequence of the well-known implications of living in a cold home for physical and mental health. The basis of the Hills methodology [9] is that well-insulated dwellings require less energy to maintain a prescribed indoor thermal comfort and this can be accounted for in building energy modeling techniques [10].

Although the Boardman method also uses modeled energy costs instead of actual bills, in the words of Hills, this is the major advantage of this type of methodology [10]. The main difference between both methods is that Hills proposed to fix the energy poverty threshold at the median energy expenditure. The BRE Domestic Energy Model (BREDEM) modeling tool, using data from the English Housing Survey (EHS), is applied to calculate the threshold of the median modeled bill [13], avoiding energy costs related to unheated spaces, e.g., due to excessive size of the building, using various heating regimes dependent on the age of the household and employment status, and adjusting for the number of occupants. A standard heating pattern, i.e., assuming that during usual working hours the house 
is empty, does not apply, in particular for the vulnerable, e.g., the elderly or those caring for young children [13]. For these cases, the full heating regime was introduced in the UK methodology. Size and number of occupants is also important; therefore, for under-occupied dwellings, partial standard/full heating regimes were included. Initially in the LIHC definition, the addition of non-heating energy uses was not clear [14]; following the unpacking of the methodology used to generate the UK's annual fuel poverty statistics these measures became more prominent. The steps involved in this methodology can be summarized as follows: income is measured without considering housing costs, the so-called after housing costs [15], the dynamic $2 \mathrm{M}$ is used for the affordability threshold. Then, the 'fuel poverty gap' is added as an additional indicator in order to consider the difference, in monetary terms, between the modeled expenditure for an energy poor household and the expenditure required to remove that household from energy poverty. Subsequently, once modeled energy (and housing) costs are deducted, those whose income is not within the 60 per cent median range are identified as energy poor [10].

Hills [9] included both energy bills and income details, and identified that they should be adjusted so that comparison to a single threshold is possible for households with different numbers of occupants, known as 'equivalization' of income measurement. Equivalization allows comparison on the same scale between households of different composition and size: decreasing the expenses of multiple person households and increasing the expenses of single person households in order to make them comparable. Income equivalization for the Organization for Economic Co-operation and Development (OECD) countries was depicted by [16]: as 1 head, 0.5 other adult, 0.3 children under 14 . In the UK methodology, income is equivalized after the discounting of housing costs [13].

To secure a good level of capabilities, the necessary amount of energy services is dependent on household size and the climate, as previously described, but also specific individuals' needs and circumstances-e.g., whether they are older, disabled, very young, or ill [2]. To account for this effect, notwithstanding heating regimes, Hills included the equivalization of energy costs. Initially, using the same factors used for income (adapted from the modified OECD scale), but as the relationship to household of size energy costs and general living costs are not the same, the idea was later rejected [9]. For instance, if the number of occupants increases by one person in an identical space, heating use would vary very little, while the cost of living would increase [9]. Furthermore, the energy demands of specific consumers can exceed the average as a result of socio-demographic factors, which can lead to their being identified as vulnerable, i.e., if they experience difficulties when accessing energy [17]. If those vulnerable characteristics are to be included, additional adjustments are needed, resulting in the equivalized theoretical energy costs. The equivalization factors for energy costs are reviewed periodically, based on three years of required fuel cost data from the EHS, but not on an annual basis [13].

On the differences between indicators, TPR is an absolute indicator, while LIHC is relative. Both TPR and LIHC have their drawbacks:

- $\quad$ TPR is a fixed ratio and very sensitive to energy prices [9];

- LIHC—smaller homes are excluded from the definition, where increases in energy prices no longer have an impact on the indicator [18]. The indicator also has a doubly-relative character, which makes it very difficult to isolate causes and effects in the process of analysis [19].

The tendency of the Hills LIHC indicator to identify low income households living in smaller dwellings was described by Moore et al. [20]. There is a disproportionate representation of households experiencing difficulty paying energy bills, and consequently under-spending on energy, resulting in lower indoor temperatures. Accounting for dwelling size is therefore critical, and a slightly different equivalization method was subsequently proposed, this method is dependent on occupancy and the dwelling size-useable floor area $\left(\mathrm{m}^{2}\right)$ [20].

Dwelling size is a key factor contributing to high energy bills, therefore, in an attempt not to underestimate this effect, the adjustment of energy costs for dwelling size was deemed inappropriate by the UK Government [13]. This is coherent with other approaches, e.g., L'Observatoire National de 
la Précarité Énergétique (ONPE) statistics [21], where the effect of occupancy on energy costs is less than the impact of size of living space.

Hills argues that, as energy prices change, the TPR results in thousands of households moving in and out of energy poverty [15]. In comparison, the LIHC gives stable results over time, and also across countries. This does not seem to be realistic with regard to the effect of energy prices and other variables: energy prices are comparable throughout the EU, energy efficiency is only dramatically superior in Nordic countries, with climate being the only factor which makes a significant difference regarding energy needs. To face their most severe weather, Finland, Norway, and Sweden impose higher energy efficiency standards [22], consequently heating costs are usually lower, and given that these costs are the most significant contributor to energy expenses, energy poverty indexes should be lower, as average income is higher. In Finland and Sweden, the "keep warm" subjective index is lower than $3 \%$ [23], whereas $2 \mathrm{M}$ retains the $15 \%$ of energy poor calculated for other European countries. In southern European countries, heating costs are high despite comparatively good weather conditions, and the "keep warm" indicator is greater than $20 \%$ in Greece and Portugal due to lower mean income, as shown in Table 1 for $2 \mathrm{M}$. Unexpectedly, $2 \mathrm{M}$ remains around $15 \%$.

The LIHC has been considered in other EU Member States as a benchmark indicator for official energy poverty statistics [11]. Rademaekers et al. [5], however, state that instead of reasonable/modeled/ theoretical energy costs, real/actual energy costs are usually used as the proxy to calculate heating expenses from official statistics. The data needed for the Hills method/LIHC indicator are provided by specially designed UK surveys; this resource-intensive and costly procedure can involve data which are difficult to obtain, making the whole process expensive. In Portugal, Spain, and Greece, for example, the current methodologies using energy poverty measurements are the following:

- Greece: no official method to identify energy poverty. The "inability to keep home adequately warm" index is monitored annually by the Hellenic Statistical Authority;

- Portugal: no official method to identify energy-poor households;

- Spain: the only available statistics at a national level are not provided by an official institution, but thanks to the Association of Environmental Sciences (Asociación de Ciencias Ambientales, ACA) [24], although using actual bills.

The EPOV performs energy poverty measurements in those three countries, and 23 more [25], based on HBS data. So, using actual energy bills.

Approaches using theoretical energy costs can be found in other countries. In France, where the production of statistics by ONPE is a resource intensive process, the indicators do not reply on modeled invoices. Moore [18] found the use of actual energy bills controversial, considering this variable as a poor indicator for energy poverty. After analyzing data on actual energy use, most households do not live at the temperatures assumed in modeling [15]. In particular, the lowest income decile appear to be living at temperatures below the "adequate" threshold [15]. Moore [18] identified that low-income householders stay in cold dwellings because they spend significantly less on fuel than required. Difficulty identifying households which under-consume energetically is widespread among most Member States; according to Florio and Teissier [26], it is difficult to identify the presence of energy restrictions, indicating lower real expenditure. Palma et al. [27] also addressed this issue of under consumption through a detailed analysis of regional energy performance gaps for the city of Évora.

The use of modeled energy costs, however, led researchers to include normative criteria in energy poverty characterization, resulting in the idea of factoring for "access to adequate energy services", given that adequacy is a normative concept [6]. The justification for this approach is that modeled energy bills are related to indoor temperatures, and these temperatures are related to health problems. However, while it is difficult to know what indoor household temperature conditions are, calculating energy costs with building efficiency data is the best way to avoid this targeting problem. It is 
therefore assumed that this problem does not exist in the UK, and consequently, the LIHC methodology prioritizes energy efficiency measures as the appropriate solution [28].

As an alternative to solve this problem of targeting, the Hidden Energy Poverty (HEP) index is used in Belgium [29]: households with an energy expenditure lower than $50 \%$ of the national median are also considered to be in energy poverty. In 2013, the index identified a notable $4.6 \%$ of the population as energy-poor. The application of this index highlights a new targeting problem, which can be clearly identified in the following two cases:

- Highly efficient buildings cause their inhabitants (be they low- or high-income households) to be considered as energy-poor by the HEP due to the low energy costs resulting from a well-insulated building;

- When comparing areas with different energy demands due to climate, those who reside in areas with a less severe climate may be considered as being in energy poverty.

Thus, although the HEP addresses the problem of targeting, it causes a problem of its own. A driver in the search for alternatives is the various drawbacks associated with the Hills LIHC indicator; i.e., Moore [20] criticized its complexity and proposed several improvements, e.g., not excluding low energy costs. Notwithstanding the methodology in UK, there are few studies dealing with the use of theoretical energy costs. With the aim of addressing this gap, Imbert et al. [21] used the French 3CL-method for modeling energy costs to investigate whether it is possible, in countries where data availability is limited, to transfer energy poverty indicators based on required energy needs.

In Greece, as in other European countries, the use of actual energy expenses underestimates the measure of energy poverty. Moreover, self-declared data are not reliable, as they often also include fuel consumed for transportation. To solve these problems, Papada and Kaliampakos [30,31] used modeled energy consumption as a variable for assessing energy poverty. There were 12 parameters that were taken into account in the Stochastic Model of Energy Poverty (SMEP) model used, e.g., heating-degree-days, coefficient of performance of heating systems, heating price, heat transfer coefficient. In Portugal, Gouveia et al. [4,32] showcased for all Portuguese civil parishes how a multidimensional energy poverty vulnerability index could be used, while combining information from buildings' energy performance (i.e., energy needs), final energy consumption, climate variables, and representative socio-economic indicators.

In France, based on the survey for Housing Performance, Equipment, Needs, and Uses of Energy PHEBUS (L'enquête Performance de l'Habitat, Équipements, Besoins et USages de l'énergie), a simplified approach by income and the French energy performance label DPE (Diagnostic Performance Energétique) was explained by Florio and Teissier [26] for energy poverty evaluation. This approach employs the relatively simple method of setting a minimum energy performance standard for the buildings (and working with the first five deciles of income, for example), similar to the Hills alternative proposal explained above. Theoretically, if the energy performance of all homes was at maximum efficiency, and if energy prices were the same for all households, energy poverty and income poverty assessment would achieve the same results [10]. DPE, however, is only compulsory when renting or selling a property, with DPE being calculated for only 3.6 million buildings in France in 2018, and not for the remaining building stock. Non-heating expenses are not included in this method, except perhaps DHW, despite there being a strong case for revaluating the significance of non-heating energy-uses [14].

This proposal has the potential to contribute to the development of an alternative approach to the current energy poverty measures with actual energy expenses; if energy efficiency standards for buildings could be made uniform across countries, this methodology could be adapted for the national indicators of each country. Theoretical energy needs are the focus of this paper, where modeled energy bills will be calculated based on building energy performance data and non-heating energy-uses, and subsequently adjusted according to socio-demographic variables, by using equivalization weights using the Hills [9] methodology. Data from three southern EU regions, i.e., Greece, Évora municipality, 
and the Basque country, will be used as case studies, with econometric analysis applied to calculate equivalization coefficients. The proposed methodology for calculating energy costs and calculations will be applied to the TPR indicator, simplifying the process to a certain extent, but not to the degree of the French DPE approach. The same approach applied to the HEP indicator facilitates the identification of households that under-consume. In order to avoid accounting for higher incomes, a cap on incomes that fall within the first five deciles can be set. This approach will avoid inaccuracies in the identification of energy-poor households.

In the remaining sections, drawing on data from different European regions, this paper will focus on measuring energy poverty following the methodology above. The remainder of the article is structured as follows: in the following section the methodology will be outlined and data sets from Greece, and the Portuguese and Spanish regions will be presented. The methodology for the econometric analysis will then be described, including an explanation of why the present work is carried out using the 2M, TPR, and HEP indicators. The results of the analysis are introduced, and subsequently the key findings and discussion are presented, highlighting how the TPR and HEP indicators can improve the identification of vulnerable homes through the use of theoretical energy costs. The article concludes with some implications for policymakers.

\section{Methodology}

In this section, details of the countries selected for the case study are provided, the methodology used for measuring energy poverty is explained, and datasets that will be tested are characterized.

\subsection{Case Studies Description}

Three case studies were used from southern Europe (i.e., Greece, the city of Évora in Portugal, and the Basque region in Spain) to showcase the methodology, presenting interesting variations in climate characteristics, income levels, and energy prices. Case study selection was based on the presence of under-consuming and availability, in some cases even those with no heating were included. The data from Greece originated from a survey performed by Papada and Kaliampakos [33] covering the whole country. For Portugal, a door-to-door survey in the municipality of Évora was used. Information on the survey conducted, type of data collected, and key insights are available in Gouveia et al. [34]. Spanish data originated from social housing in the Basque region, accessible through the public company's databases. Used here for the first time, it was collected in 2019, comprising data from 2018.

A summary of the most relevant variables can be found in Table 1. Population data were sourced from Eurostat [35] for Greece, Portugal, Spain, and the Basque country, and PORDATA for Évora municipality [36]. The number of households was taken from Eurostat [35] (lfst_hhnhtych) for Greece, Portugal, and Spain, Eustat [37] for the Basque country, and PORDATA for Évora municipality [36]. Climate variables were heating degree days (HDD) and cooling degree days (CDD) calculated at $15.5^{\circ} \mathrm{C}$. Energy prices, including taxes for households (band for electricity between 2500 and $5000 \mathrm{kWh} / \mathrm{yr}$. and for gas between 20 and $200 \mathrm{GJ} / \mathrm{yr}$.) were taken from the Eurostat [35]; average gas (nrg_pc_202) and electricity prices (nrg_pc_204) for the years 2016-2018. The income variable for the countries represented the adjusted gross disposable income of households per capita taken for Eurostat, while data for the city of Évora were taken from Portuguese National Statistics Office (INE) [38], and from Spanish INE for the Basque country [39]. The most relevant energy poverty indicators for Greece, Portugal, and Spain were taken from the EPOV database for latest data available [25], and referred to a percentage of the population. There were no official data available for energy poverty levels in the city of Évora, but ACA included disaggregated results for Spanish regions when calculating energy poverty indicators for Spain with data of 2016 [24]. 
Table 1. Summary of most relevant variables in Greece, Évora municipality (Portugal), and Basque region (Spain).

\begin{tabular}{|c|c|c|c|c|c|}
\hline & Greece & Portugal & City of Évora & Spain & Basque Region \\
\hline Population $2018^{1}$ & $10,741,165$ & $10,291,027$ & $52,664^{2}$ & $46,658,447$ & $2,170,868$ \\
\hline Number of households $2018^{1}$ & $4,348,100$ & $3,910,800$ & $29,812^{2}$ & $17,384,300$ & $1,054,610^{3}$ \\
\hline HDD (inland) $2108^{4}$ & 1390 (Ioannina) & - & 1050 & 1500 (Madrid) & 1980 (Vitoria) \\
\hline HDD (coast) $2018^{4}$ & 650 (Athens) & 675 (Lisbon) & - & 970 (Barcelona) & 955 (Bilbao) \\
\hline CDD (inland) $2018^{4}$ & 1060 (Ioannina) & - & 1185 & 1355 (Madrid) & 535 (Vitoria) \\
\hline CDD (coast) $2018^{4}$ & 1675 (Athens) & 970 (Lisbon) & - & $\begin{array}{c}1340 \\
\text { (Barcelona) }\end{array}$ & 875 (Bilbao) \\
\hline $\begin{array}{l}\text { Electricity price, } € \text { per } \mathrm{kWh} \text {, } \\
2016-2018^{1}\end{array}$ & 0.168 & 0.228 & $0.228^{5}$ & 0.23 & $0.23^{5}$ \\
\hline $\begin{array}{l}\text { Gas price, } € \text { per } \mathrm{kWh}, \\
2016-2018{ }^{1}\end{array}$ & 0.059 & 0.081 & $0.081^{5}$ & 0.077 & $0.077^{5}$ \\
\hline $\begin{array}{l}\text { Adjusted gross disposable } \\
\text { income of households per } \\
\text { capita, 2016, } €^{1}\end{array}$ & 14,622 & 17,686 & $16,644^{7}$ & 19,216 & $25,121^{6}$ \\
\hline $\begin{array}{l}\text { High share of energy } \\
\text { expenditure in income }(2 \mathrm{M}) \\
\text { Population }(\%), 2015^{8}\end{array}$ & 16.3 & 15.1 & $\mathrm{n} / \mathrm{a}$ & 14.2 & $9.0^{9}$ \\
\hline $\begin{array}{l}\text { Low absolute energy } \\
\text { expenditure (M/2), Population } \\
(\%), 2015^{8}\end{array}$ & 12.8 & 6.8 & $\mathrm{n} / \mathrm{a}$ & 13.0 & $5.0^{9}$ \\
\hline $\begin{array}{l}\text { Inability to keep home } \\
\text { adequately warm, Population } \\
(\%), 2016^{8}\end{array}$ & 29.1 & 22.5 & $\mathrm{n} / \mathrm{a}$ & 10.1 & $6.0^{9}$ \\
\hline $\begin{array}{l}\text { Arrears on utility bills, } \\
\text { Population }(\%), 2016^{8}\end{array}$ & 42.2 & 7.3 & $\mathrm{n} / \mathrm{a}$ & 7.8 & $6.0^{9}$ \\
\hline
\end{tabular}

With regard to the differences across countries, HDDs are higher in Spain, both inland and coastal areas. When comparing countries and regions, the Basque inland is colder than Madrid, and the city of Évora is considered average, as the Portuguese inland regions do not vary significantly in terms of altitude. The CDDs are greatest for the coastal areas of Greece and Spain, as the Spanish inland region is as hot as the coastal area during summer and the Greek inland area much colder. The Basque country is much colder than the rest of Spain during summer. Overall, with regard to climate data, the city of Évora is representative of the Portuguese inland regions, while the Basque region is one of the coldest in Spain.

Average income is highest in Spain and lowest in Greece; the same applies to household energy prices. The disposable income in the city of Évora is only slightly below the national average. Comparatively, however, income in the Basque region is the highest.

The energy poverty indicators take similar values when using relative methodologies, i.e., for $2 \mathrm{M}$ around $15 \%$, but the self-perceived "inability to keep home adequately warm" is different across countries, following the inverse order of mean income. The "arrears on utility bills" indicator is disproportionately high in Greece. In the absence of official data for Évora, the only analysis on energy poverty analysis for Portuguese regions was conducted by Gouveia et al. [4]. In this study, the Energy Poverty Vulnerability Index (EPVI) was used to map and rank vulnerability to energy poverty in all Portuguese regions, both in the winter and in the summer. Their latest results revealed that the municipality of Évora is ranked 271st (for winter vulnerability) and 287th (for summer vulnerability) of a total of 308 municipalities. These results show that Évora is on the lower end of the vulnerability spectrum in the heating and cooling seasons, this can be explained by a higher adaptive capacity and lower energy performance gaps in comparison with other Portuguese regions. Finally, for the Basque country, very probably as a result of higher disposable household incomes, all the energy poverty indicators are lower. 
To summarize, while the city of Évora is representative of Portugal regarding climate and income, the energy poverty levels are lower. The results of the Basque Country are not representative of the rest of Spain, due to the colder climate, higher incomes, and lower energy poverty levels.

\subsection{Research Method}

The research hypothesis tested in the following section contests that modeled energy bills can be adjusted to actual energy expenses according to socio-demographic variables. Certain sociodemographic variables increase energy needs, for example, householders maintaining higher indoor temperatures and/or spending longer periods of time at home, the make-up of such households usually includes: (a) children under 18 years old, and (b) elderly and/or pensioners [13]. These households also very often include unemployed people and/or a dependent householder.

For this reason, analysis to find correlations between actual energy bills and socio-demographic variables was first performed using data from Greece, and two regions in Portugal and Spain. The correlations between each of the variables and actual energy bills were accepted or rejected using Spearman and Pearson analyses.

Subsequently, equivalization weights were calculated through an econometric analysis, so as to adjust socio-demographic variables with the actual energy expenditure and theoretical energy costs based on the available data, explained in the next section. A positive correlation between a variable and the actual energy consumption, e.g., a higher occupancy usually means higher energy consumptions, should increase the modeled energy bills. Therefore, through the econometric analysis, equivalization weights for socio- demographic characteristics were calculated.

The proposed econometric model for the regression needed to calculate those equivalization factors is described in Equation (1):

$$
\log (\text { Actual energy bills })=\beta_{1} \times \log (\text { Modeled energy bills })+\Sigma_{\mathrm{i}} \beta_{\mathrm{i}} \mathrm{x}_{\mathrm{i}}+\varepsilon_{\mathrm{i}},
$$

where "Actual energy bills" is the dependent variable actual energy expenses, "Modeled energy bills" represents the energy costs calculated theoretically, $x_{i}$ are the explanatory variables (occupancy, area. and the socio-demographic variables as binary variables, namely, the presence of children and/or elderly, also including pensioners/retired and unemployed wherever possible), and $\varepsilon_{\mathrm{i}}$ is the error term. In order to adjust the model, $\beta_{i}$ coefficients are attained from the regression. This approach is the model commonly proposed, e.g., by [40].

Heating/cooling energy needs will be explained in the next section, and they are introduced as kWh per dwelling. Sunikka-Blank and Galvin [41] proposed using kWh per dwelling/year instead of using energy consumption per square meter $\left(\mathrm{kWh} / \mathrm{m}^{2} \mathrm{yr}\right)$ : they affirmed that in this way more information is given about consumers, as heating expenses depend on both the consumption per square meter and the size of the dwelling. ONPE also proposes both units to express the energy costs of the households, and for the case of LIHC/UC the equivalization considers household size and composition. However, the equivalization scale is not mentioned by ONPE [21].

Area was included as a variable in the analysis, as it is a common explanatory variable of energy consumption [41]. Occupancy is the second common variable when analyzing energy consumption, for example, through the BREDEM modeling tool, as explained in the introduction.

The socio-demographic variables were binary variables, therefore multivariate regression was used. It was possible to calculate the percentage increase resulting from each of the variables, facilitating the calculation of equivalization weights for of each of the socio-demographic variables. In order not to calculate biased coefficients, since the objective was to obtain a modeled energy bill, this econometric analysis was performed for an average consumer for each of the countries, so that specific characteristics were not overrepresented, e.g., excessively low/high energy consumptions due to low/high income. In doing this, the aim of building modeled energy bills adjusted to vulnerability variables was realized. 
In order to compare energy poverty levels using actual energy bills against reasonable energy costs, the obtained coefficients were incorporated in the modeled energy bills. The comparison between modeled energy bills with and without coefficients was also carried out. With regard to the indicator applied, although both the TPR and the LIHC have disadvantages, use of the former is justifiable. The introduction highlighted that, in inter-country comparison, 2M methodologies -including LIHCdo not capture the impact of energy prices on heating bills over time, other impacts, such as differences, in climate data are also omitted. The TPR was considered a good alternative given that it is intuitively understood by many. Subsequently, the analysis to test the functionality of the current methodology was carried out by calculating the TPR using actual expenses versus modeled energy bills, with and without equivalization coefficients.

Additionally, this methodology for calculating reasonable energy costs can be used to identify those under consuming by comparing energy poverty measurements using actual expenses with measurements using theoretical energy needs adjusted with socio-economic variables. For Rademaekers et al. [5], under-consumption occurred when households did not spend enough to achieve a certain standard of energy services. Here, the definition assumed for under consumption was similar to the HEP indicator, this is $\mathrm{M} / 2$, but referred to modeled energy costs, and introducing a cap on income, this is considering only the first five deciles. If HEP underlined the existence of self-rationing practices [29], defined in HEP methodology as those consuming less than half the median $(\mathrm{M} / 2)$, in an analogous manner, in this article it was assumed that a household was under consuming when consuming $50 \%$ of the theoretical energy cost or less. Considerations about using theoretical energy costs instead of actual expenses then applied equally to the HEP indicator.

\subsection{Data Set}

Firstly, the data used in the correlation analysis are presented.

Regarding actual expenses, occupancy, size of the dwelling, and socio-economic variables, data sources for each country/region are provided below:

- For Greece, survey data from Papada and Kaliampakos [33] comprise 400 households across all of Greece, with data available on actual and required energy costs, income, building characteristics (type and size, main heating system, year of construction, region, and altitude), and some social variables (occupancy and age ranges, gender and presence of pensioners and/or unemployed). Raw data were used for the analysis performed, as recalculation of energy costs with supplementary information was unnecessary. All data were complete. The correlations between actual energy expenses and the following variables were analyzed: young under 18 years old, pensioners, people over 60, and unemployed.

- In Portugal, a door-to-door survey of 388 households was performed in the municipality of Évora [34]. DHW was included as well as cooking, lighting, and electrical devices. Daily registry information from smart meters (2014-2017) was also available for this household dataset, therefore electricity consumption was retrieved for better understanding of the levels of consumption. Average electricity consumption in the sampled households was $3682 \mathrm{kWh}$ [42], which represents $44 \%$ of total energy consumption, i.e., the average total energy consumption is $8350 \mathrm{kWh}$; from this total, DHW is usually non-electric and reaches $2613.5 \mathrm{kWh}$ on average, approximately half of the $3081 \mathrm{kWh}$ for cooking comes from electricity, electrical appliances represent $1361 \mathrm{kWh}$ in electricity, and lighting an additional $560 \mathrm{kWh}$. Average data were used to fill the information gaps in actual energy expenses, in cases where no real data were available. The sample of 388 households was reduced to a final sample of 219 households, as some data from the survey were incomplete. From those 219 households, occupancy in the city of Évora was unknown for three data points and $\mathrm{m}^{2}$ for one data point. The under 18 variable was available in this case study, as was the under 4 category, both were therefore analyzed but only the first could be compared with Greek data. There were no data available for the over 60 category, with data instead being available for 
the over 65 age group, there was no unemployment data available. Income data were available for analysis for only 145 households.

- In Spain, actual energy costs were taken from unpublished social housing data in the Basque region, including heating, DHW, and electricity. No cooling systems are installed in the building blocks. For all the tenants sharing a street number (same main entry to the building), only average (but real) electricity expenses were known. For the socio-demographic variables, occupancy was unknown for three data points. The analysis of the under 4, under 18, and over 65 categories was possible, but age registration is problematic at the Basque social housing company, Alokabide, as age data should be provided by the holder of the contract during the signing of the rental agreement, and often not all the occupants are registered. Our analysis revealed that data for the under $4 \mathrm{~s}$ and the under $18 \mathrm{~s}$ were only available for 489 households, and for 505 households for the over $65 \mathrm{~s}$. There were no unemployment data available.

In summary, with regard to the socio-economic variables, the age of the occupants was categorized into an under 18 group for all three cases, and an under 4 category (data for this group was only available for Portuguese and Spanish regions). Similarly, while it was possible to analyze the People over 65 category in Évora and the Basque country, in Greece data were only available for People over 60. Data for the Pensioner category was only possible for Greece and Évora, and an Unemployment category only for Greece.

Regarding the proxies of the econometric analysis, actual expenses, occupancy, size of the dwelling, and socio-economic variables were the variables explained above.

Theoretical energy costs were standardized to make comparable data from the different surveys, in the following way. The reasonable energy expenses for Greece and the Spanish case were calculated following the approach introduced by Papada and Kaliampakos [30], where the required energy cost was calculated by applying the "Stochastic Model of Energy Poverty" (SMEP) to a representative sample of households in Greece, all of them characterized by the twelve input variables of the model, such as income, energy price, or physical characteristics of the buildings, to calculate space heating and cooling, DHW, cooking, lighting, and other electrical equipment. In brief, the SMEP model calculated energy needs for heating/cooling, electricity and DHW. Heating/cooling energy needs were obtained through degree-days and energy performance of the building, as shown in Equation (2):

$$
\mathrm{E}_{\text {needs }}=\frac{\mathrm{H}_{\text {tot }}}{\mathrm{n}_{\mathrm{H}}} \times \mathrm{HDD} \times \frac{24}{1000}
$$

where $\mathrm{H}_{\text {tot }}$ is the coefficient of heat transfer due to convection and also ventilation-a good approximation is achieved by entering basic data for a building (area, type of building, year of house construction) - HDD is heating degree days (CDD for cooling degree days), and $\mathrm{n}_{\mathrm{H}}$ is the efficiency of the heating energy system ( $n_{C}$ for cooling).

- In the Greek case, required energy costs were already calculated by Papada and Kaliampakos [33], including building characteristics (type and size, main heating system, year of construction), region, and altitude. To calculate energy needs in Greece, typical consumption values were taken for DHW, cooking and the rest of the data needed lighting and other electrical devices.

- For the city of Évora, $\mathrm{H}_{\text {tot }}$ was not available. To render the data compatible with Greek and Spanish datasets, energy needs for heating/cooling were obtained using energy performance calculations from a regional building sample, calculated based on the raw information areas, bearing structure, insulation type, windows type, etc., available in the energy performance certificates following a stationary approach, extensively described in Palma et al. [27]. The rest of the energy needs were taken from the averages outlined above.

- In the Basque region, theoretical energy costs were calculated using the methodology of Papada and Kaliampakos [30]. In this case, the energy performance of the buildings was taken from the overall heat transfer coefficient of the building envelope ( $\mathrm{U}$-value), very similar to $\mathrm{H}_{\text {tot }}$. Climate data 
(HDD and CDD) were available for each case. Data were sourced from multiple-occupancy buildings, therefore, required energy needs were recalculated for some of the dwellings, i.e., those with no heated spaces usually below a garage or commercial spaces to rent at street level need $60 \%$ more energy, and certain dwelling orientations-facing north increases consumption by $25 \%$ while facing south has no influence. On the contrary, there was no need to introduce modifications for top-floor dwellings under the roof. Theoretical needs for DHW were calculated according to the Spanish technical code of buildings CTE for multi-occupancy buildings [43], 28 liters per day and person at a temperature of $60{ }^{\circ} \mathrm{C}$. Electricity needs were taken from average regional consumptions statistics (Basque entity for energy) [44], $3100 \mathrm{kWh}$ was included in the theoretical energy needs for electricity.

Given that the econometric analysis was performed for an average consumer for each of the countries, in the end this meant discarding some data, e.g., the lowest income levels were not considered so that excessively low energy consumptions were not overrepresented. The following data were used to calculate the theoretical energy needs:

- In the Greek case, according to the Real Disposable Household Income by Income Decile [45], incomes over $€ 4000$ and under $€ 30,500$ were avoided, resulting in a dataset comprising 342 households for the econometric analysis;

- For Évora municipality, as only four income ranges were available, all data were taken into account;

- In the Basque region, as the data source was the social housing register for rental properties, low income households were over-represented: $€ 25,000$ is the income cap for accessing social housing, but it is weighted depending on the number of householders, reaching up to $€ 50,000$ for a household of eight members; the maximum in the data set was $€ 38,000$. Analysis of the entire dataset would lead to biased results. The average family income in the Basque region was $€ 35,049$ in 2018 [39], only data from households with an income weighted according to modified OECD scale over $€ 15,000$ were used. Therefore, in order to increase the representativeness of the Basque social housing and to make it applicable to the remainder of the housing stock, only 133 data points were accounted for in analysis. Initially, complete datasets were only available for 96 dwellings in the database from the social housing company, there was also an overrepresentation of single person households as it is easier to obtain complete datasets for this group. Data for 22 multiple person households were completed through telephone calls and single person households were deleted. In the end 115 data points were used in this analysis.

\section{Results}

Spearman and Pearson analyses were used to confirm or reject the relationships between variables. Calculations for correlations, both Spearman and Pearson, can be found in Appendix A. As Pearson is used for linear correlations, and the econometric analysis will be linear for the logarithms of consumption, the test was performed for the logarithm of the actual energy expenses. Each of the independent variables will follow a linear Equation (1) when calculated correlation coefficients are closer to 1 or -1 , the correlation is strong if greater than 0.5 or less than -0.5 .

Regarding the correlations of the variables in Greece, shown in Table A1 (Appendix A), none of them seemed to follow a linear relationship individually with respect to actual energy costs (log), and the coefficients obtained were not significant for the over 60 and unemployed variables. Linearity was higher in the case of dwelling size. Unsurprisingly, a positive correlation was obtained for two variables, occupancy and size $\left(\mathrm{m}^{2}\right)$; the energy consumption increases as dwelling size increases and as the number of household members increases. For the socio-demographic variables, no clear trend can be discerned. Two of these variables targeted similar segments of the population, specifically the pensioner and people over 60 categories, where the former was a better predictor.

Results for the Portuguese municipality are shown in Table A2. Data for the number of occupants variable were missing for three households and the size was unknown for another household. 
The calculated coefficients were slightly higher. With regard to socio-economic variables, the pensioner and over 65 categories were equally good indicators. There were two variables for the youngest portion of the population, the analysis showed that children under 18 years old was a more accurate indicator and will be used for the regression.

Finally, the results for the Spanish sample analysis are shown in Table A3. The explanation above highlighted that there were three data points missing for occupancy, and many more for socio-economic variables. The coefficients obtained were very close to zero, especially in the case of the size of the dwelling. There was also no clear trend for the over 65 category. Like the previous case, children under 18 years old was a better indicator and will be used for the regression.

In terms of the econometric analysis, the results were as follows. Starting with the case study in Greece, six more data points were discarded due to households not having heating. The Spearman test was repeated and the results for the previous correlations were maintained, with the exception of the unemployment correlation, as only 5 cases out of 342 households were registered as unemployed.

Apart from occupancy and dwelling size $\left(\mathrm{m}^{2}\right)$, the binary variables "children under 18 " and "pensioners" were included in the regression analysis explained above, multivariate regression was applied, as it was the most suitable for the type of variables analyzed. The output is presented in Equation (1), with Table 2 showing the regression results:

Table 2. Multivariate regression for Greek data.

\begin{tabular}{lccccc}
\hline \multicolumn{1}{c}{ Dependent Variables } & Number of Observations & RMSE & “R-sq" & F & $p$ \\
\hline Actual energy expenses $(\log )$ & 342 & 0.237797 & 0.9946 & 12529.53 & 0.0000 \\
\hline Independent Variables & Coefficients & Std. Err. & $\boldsymbol{p}>\mathbf{| t |}$ & $\mathbf{( 9 5 \% \text { conf. interval) }}$ \\
\hline Required energy needs $(\log )$ & 0.9010211 & 0.0178635 & 0.000 & 0.8658832 & 0.9361591 \\
Area of the dwelling & 0.0010963 & 0.0004215 & 0.010 & 0.0002673 & 0.0019253 \\
Occupancy & 0.029178 & 0.144352 & 0.044 & 0.0007836 & 0.0575725 \\
Children under 18 & 0.0766169 & 0.0336837 & 0.024 & 0.01036 & 0.1428737 \\
Pensioners & -0.0063797 & 0.0366709 & 0.862 & -0.0785124 & 0.0657531 \\
\hline
\end{tabular}

The results of the econometric regression were converted into the coefficients, as corresponds to Equation (1), i.e., converting the logarithmic coefficients to their exponential format, and were follows:

- The required energy costs over-estimate the actual energy cost by $53.6 \%$ (significant at the 0.01 level) on average, depending on the required energy needs;

- For the size of the dwelling, every additional $20 \mathrm{~m}^{2}$ signifies a $5 \%$ increase in energy consumption (significant at the 0.05 level);

- Every additional household member increases energy consumption by $7 \%$ (significant at the 0.05 level);

- Having children under 18 years old increases energy consumption by $19.3 \%$ (significant at the 0.05 level);

- The presence of a pensioner decreases energy consumption by $0.6 \%$ (although not statistically significant).

For the city of Évora, the econometric analysis was performed for 145 households. After repeating the Spearman test, the correlations were maintained, and the coefficients from the regression were the following in Table 3: 
Table 3. Multivariate regression for Portuguese data (Évora municipality).

\begin{tabular}{lccccc}
\hline \multicolumn{1}{c}{ Dependent Variables } & Number of Observations & RMSE & “R-sq" & F & $p$ \\
\hline Actual energy expenses (log) & 145 & 0.096911 & 0.9994 & 46263.29 & 0.0000 \\
\hline Independent Variables & Coefficients & Std. Err. & $\boldsymbol{p}>\mathbf{| t |}$ & $\mathbf{( 9 5 \% \text { conf. interval) }}$ \\
\hline Required energy needs (log) & 0.9165098 & 0.0067497 & 0.000 & 0.9031653 & 0.9298543 \\
Area of the dwelling & -0.0015793 & 0.0001163 & 0.000 & -0.0018092 & -0.0013494 \\
Occupancy & 0.0279772 & 0.0084188 & 0.001 & 0.0113328 & 0.0446217 \\
Children under 18 & 0.0114331 & 0.0227603 & 0.616 & -0.0335653 & 0.0564315 \\
Retired & 0.0147099 & 0.0181354 & 0.419 & -0.0211447 & 0.0505645 \\
\hline
\end{tabular}

Following the same method that was applied to the Greek data, the results of the econometric analysis with the Portuguese data are the following:

- The required energy costs over-estimate the actual energy cost by $56.8 \%$ on average (significant at the 0.01 level);

- The energy consumed decreases $7 \%$ (significant at the 0.01 level) with every additional $20 \mathrm{~m}^{2}$;

- Every additional household member increases energy consumption by $6.5 \%$ (significant at the 0.01 level);

- Having children under 18 years old increases energy consumption by $2.7 \%$ (not statistically significant);

- The presence of a pensioner increases energy consumption by $3.4 \%$ (not statistically significant).

In the case of the Spanish data, as explained in the methodology, the econometric analysis was performed for 115 households. The Spearman test was repeated, the previous correlations were maintained. Table 4 presents the results of the regression performed:

Table 4. Multivariate regression for Basque data.

\begin{tabular}{lccccc}
\hline \multicolumn{1}{c}{ Dependent Variables } & Number of Observations & RMSE & “R-sq" & F & $p$ \\
\hline Actual energy expenses (log) & 115 & 0.2092903 & 0.9971 & 7517.448 & 0.0000 \\
\hline Independent Variables & Coefficients & Std. Err. & $\boldsymbol{p} \boldsymbol{>}|\mathbf{t}|$ & $\mathbf{( 9 5 \% \text { conf. interval) }}$ \\
\hline Required energy needs (log) & 0.990805 & 0.0297887 & 0.000 & 0.9317707 & 1.049839 \\
Area of the dwelling & -0.0022257 & 0.0016796 & 0.188 & -0.0055542 & 0.0011028 \\
Occupancy & -0.0130342 & 0.032414 & 0.688 & -0.0772712 & 0.0512028 \\
Children under 18 & 0.0535048 & 0.0783668 & 0.496 & -0.1017998 & 0.2088093 \\
Over 65 & 0.1417768 & 0.066138 & 0.034 & 0.0107068 & 0.2728468 \\
\hline
\end{tabular}

After calculating the coefficients, the results of the econometric regression for the Spanish data are shown below:

- The required energy costs over-estimate the actual energy cost by $8.1 \%$ (significant at the 0.01 level);

- Energy consumed decreases by $10 \%$ with every additional $20 \mathrm{~m}^{2}$ (not statistically significant);

- Every additional household member decreases consumption by $3 \%$ (not statistically significant);

- Having a child under 18 years old increases energy consumption by $13 \%$ (not statistically significant);

- The presence of a pensioner increases energy consumption by $39 \%$ (significant at the 0.05 level).

For example, when comparing coefficients between case studies, in Table 5 the effect of size is presented for the analyzed cases with regard to a couple without dependent children in Table A4 (Appendix B) with a value of 1.00, and the values revised by Moore et al. [20] for the case of two people in Table A5 (Appendix B) from 70-89 $\mathrm{m}^{2}$ to $90-109 \mathrm{~m}^{2}$, for two people from 1.00 to 1.08 are also added. 
Table 5. Proposed increase by Moore et al. [20] for two people from 70-89 $\mathrm{m}^{2}$ to $90-109 \mathrm{~m}^{2}$, compared with results in this article for couple without dependent children.

\begin{tabular}{lcccc}
\hline Household Type & $\begin{array}{c}\text { Increase by } \\
\text { Moore et al. [20] }\end{array}$ & $\begin{array}{c}\text { Variation for the } \\
\text { Case of Greece }\end{array}$ & $\begin{array}{c}\text { Variation for the } \\
\text { Case of Évora }\end{array}$ & $\begin{array}{c}\text { Variation for the Case of } \\
\text { the Basque Country }\end{array}$ \\
\hline $\begin{array}{l}\text { Couple without } \\
\text { dependent children }\end{array}$ & $+8 \%$ & $+5 \% * *$ & $-7 \% *$ & $-10 \% \mathrm{~ns}$ \\
\hline
\end{tabular}

* significant at the 0.05 level, ** significant at the 0.01 level, and ns not statistically significant.

To sum up and compare with variables proposed by Hills [9], Table 6 consolidates all the results from the econometric analysis, collecting the calculated coefficients for Greece, Évora, and the Basque country, for additional household member these are, respectively, $7,6.5$, and $-3 \%$, and for the presence of children under 18 years old 19, 2.7, and 13\% for the comparison of energy consumption drivers.

Table 6. Comparison between equivalization coef. of Hills [9] and those obtained in this article for the case studies.

\begin{tabular}{|c|c|c|c|c|}
\hline Household Type & Increase by Hills [9] & $\begin{array}{c}\text { Equivalization Factor } \\
\text { Greece }\end{array}$ & $\begin{array}{c}\text { Equivalization Factor } \\
\text { Évora }\end{array}$ & $\begin{array}{c}\text { Equivalization } \\
\text { Basque Factor }\end{array}$ \\
\hline $\begin{array}{l}\text { Couple without } \\
\text { dependent children }\end{array}$ & 1.15 & $\mathrm{n} / \mathrm{a}$ & $\mathrm{n} / \mathrm{a}$ & $\mathrm{n} / \mathrm{a}$ \\
\hline $\begin{array}{l}\text { Couple without } \\
\text { dependent children }\end{array}$ & 1.00 & 1.00 & 1.00 & 1.00 \\
\hline Lone parent & 0.94 & $0.93 *$ & $0.93^{* *}$ & $1.03 \mathrm{~ns}$ \\
\hline Single person & 0.82 & $0.74 *$ & $0.91 \mathrm{~ns}$ & $0.90 \mathrm{~ns}$ \\
\hline $\begin{array}{l}\text { Other multi-person } \\
\text { household }\end{array}$ & 1.07 & $1.07^{*}$ & $1.07 * *$ & $0.97 \mathrm{~ns}$ \\
\hline
\end{tabular}

* significant at the 0.05 level, ${ }^{* *}$ significant at the 0.01 level, and ns not statistically significant.

Finally, the calculated coefficients were applied to the following indicators:

- $\quad 2 \mathrm{M}$ and HEP with actual bills (M/2), ratio of actual to median energy bills;

- TPR with actual bills, ratio of actual energy bills to income;

- $\quad$ TPR with modeled bills, ratio of modeled energy bills to income;

- $\quad$ TPR with modeled bills with equivalization coefficients, ratio of equivalized modeled energy bills to income;

- HEP with modeled bills, ratio of actual to modeled energy bills;

- HEP with modeled bills with equivalization coefficients, ratio of actual to equivalized modeled energy bills.

The equivalization coefficients were only applied when significant. The energy indicators for Greek data were calculated using all households, whereas for Portuguese data only using those with known incomes were included. In the Basque region, the dataset accounted for 1205 households in total, excluding not available or zero incomes. The cap on incomes for TPR and HEP was set at $€ 15,000$ for Greece ( 247 out of 400 data), at $€ 18,000$ for the city of Évora (117 out of 145 data), income was not disaggregated in detail for Greek and Portuguese data, and $€ 15,000$ for the Basque region (1072 out of 1205 data).

\section{Discussion}

The first observation to make from this analysis is that the modeled energy bills are overestimated, especially in the case studies of Greece and the city of Evora. The difference between the modeled energy consumption and the real one is a circumstance well noted in the literature [41].

With regard to the dwelling area results, the expected increase was only evident with the Greek data. Neither the Spanish nor the Portuguese results were consistent with the work of Moore et al. [20]—coefficients presented in Table A5 (Appendix B). The area of the analyzed Spanish 
dwellings was limited to a narrow range size between 48 and $90 \mathrm{~m}^{2}$ as data originated from social tenants living in multiple-occupancy buildings, big families are not always in the largest dwellings and single people are not always in smallest ones, this occurs because housing is allocated according to the order of listing, this phenomenon can affect the results. To determine the reason for the results obtained for the city of Évora, this could be due to the fact that information gaps for cooking and DHW have been substituted with an average value, but a deeper analysis is needed to confirm this.

In terms of the effect of socio-economic variables, the occupancy variable has approximately the same positive energy consumption rises as occupancy increases influence across the countries/regions studied, except maybe in the Basque country where, despite not being statistically significant, the effect is negative rather than positive. Other research groups studying occupancy also observed an increase in energy consumption as the number of occupants increases; using data for France, Raynaud [46] recorded an elasticity for occupancy in individual houses of 0.2, Bair et al. [40] also include occupancy recording a $9 \%$ increase per person, and finally Denjean [47] stated that a two-person household consumes an additional $22 \%$, in a three-person house this increases to $34 \%$.

The remaining variables analyzed were related to the age of the occupants. The presence of children demonstrated a positive effect—energy consumption increased if children lived in the dwelling. These results, however, were quite varied, as the coefficients in two out of the three cases were not significant. The older population demographic was included in both the pensioner and people over 65 variables; despite the overlap in these groups the results were mixed, with a neutral effect observed in Greece around zero and not significant, a positive but not significant effect in Évora, and a significantly positive effect in the Spanish case. Occupant age is a discussion point in the literature, although this is mainly focused on the head of the household. Cavailhes [48], using data from l'Enquête National des Logements (ENL), estimated a 5\% increase in energy consumption for every 10-year age increase for the head of household. Based also on the ENL, Risch and Salmon [49] calculated for the same sample an elasticity of 0.1-0.2. Bair et al. [40], working with the PHEBUS survey, obtained similar results, a 3\% increase for each 10-year age gain. Denjean [47] calculated an increase of $13 \%$ where the head of household was over 65. In brief, the results in this article for the presence of children demonstrate consistency with the findings of other research groups, with the effect of elderly residents remaining unclear.

The results in Table 5, on the comparison between the values from Moore et al. [20] for the case of two people and a couple without dependent children in the countries/regions analyzed, reflect the combined effects of size and occupancy. The coefficient from the regression analysis for Greece was comparable although slightly lower than the one proposed by Moore et al. [20], while coefficients obtained for the Portuguese and Spanish regions were negative. Finally, after calculating the combined effects with occupancy, the influence of the area variable was maintained.

In reference to the calculated equivalization factors, Hills [9] proposed the values shown in Table A4 (Appendix B). Table 6 shows that despite the differences in the effect of the size of the dwelling across countries/regions explained above, calculated results are comparable. This is due to the fact that Hills did not take this variable into account. The results in this article for Greece and the city of Évora take comparable values to the equivalization coefficients proposed by Hills, but slightly different for the Basque region. These equivalization factors were calculated by S. Tirado et al. [50] for Poland and Spain, and the results were also slightly different for Spain.

\section{Measuring Energy Poverty Using Actual Energy Bills Against Reasonable Energy Costs}

In Table 7, the TPR and HEP are compared against $2 \mathrm{M}$. The calculated $2 \mathrm{M}$ values represent low percentages, and despite the cap on income variable, TPR and HEP indexes take high values, which is related to low-income households being overrepresented. The incomes in Greece and the city of Évora were not known accurately, this variable was therefore defined by certain ranges, which affected the results obtained. The modeled bills were over-estimated in Greece and the city of Évora, and as a 
consequence their TPR and HEP indexes resulted in higher percentages of energy poverty compared to indexes calculated with equivalized modeled energy bills.

Table 7. Comparison between energy poverty measurement methodologies.

\begin{tabular}{|c|c|c|c|c|}
\hline & Index & Greece & Évora (Portugal) & Basque Country (Spain) \\
\hline $2 \mathrm{M}$ & Ratio actual bills/median & 33 out of $400(8.2 \%)$ & 4 out of $145(2.8 \%)$ & 39 out of $1205(3.2 \%)$ \\
\hline \multirow{3}{*}{ TPR } & Actual bills & 190 out of $400(47.5 \%)$ & 60 out of $145(41.4 \%)$ & 428 out of $1205(35.5 \%)$ \\
\hline & Modeled bills & 228 out of $400(57 \%)$ & 116 out of $145(80 \%)$ & 762 out of $1205(63.2 \%)$ \\
\hline & Modeled bills with equiv. coef. & 192 out of $400(48 \%)$ & 99 out of $145(68.3 \%)$ & 715 out of $1205(59.3 \%)$ \\
\hline \multirow{3}{*}{ HEP } & $\mathrm{M} / 2$ & 32 out of $400(8 \%)$ & 5 out of $145(3.4 \%)$ & 62 out of $1205(5.1 \%)$ \\
\hline & Modeled bills & 64 out of $400(16 \%)$ & 112 out of $145(77.2 \%)$ & 232 out of $1205(19.3 \%)$ \\
\hline & Modeled bills with equiv. coef. & 33 out of $400(8.3 \%)$ & 12 out of $145(8.3 \%)$ & 197 out of $1205(16.3 \%)$ \\
\hline \multirow{8}{*}{$\begin{array}{c}\text { Households } \\
\text { with no heating }\end{array}$} & Total & 6 out of 400 & 1 out of 145 & 17 out of 1205 \\
\hline & Non energy-poor for $2 \mathrm{M}$ & 6 out of 6 & Yes & 17 out of 17 \\
\hline & Non energy-poor for TPR actual & 3 out of 6 & No & 15 out of 17 \\
\hline & Non energy-poor for TPR model & 2 out of 6 & No & 5 out of 17 \\
\hline & Non energy-poor for TPR model + coef & 3 out of 6 & No & 4 out of 17 \\
\hline & Non energy-poor for HEP median & 3 out of 6 & Yes & 5 out of 17 \\
\hline & Non energy-poor for HEP model & 4 out of 6 & No & 1 out of 17 \\
\hline & Non energy-poor for HEP model + coef & 5 out of 6 & Yes & 2 out of 17 \\
\hline
\end{tabular}

In the case of the TPR indexes, the obtained results when using actual bills were lower for all the cases studied. This means some actual bills are lower than their corresponding equivalized modeled bills. This was also evident when the actual bills were compared with their median $(\mathrm{M} / 2)$ or with their corresponding equivalized modeled bills (HEP). For each case study, the following analysis will discuss if households with no heating were correctly identified by the indicators.

In Greece, all the indicators had high values. This article used households with no heating as an example to compare different indexes, $2 \mathrm{M}$ did not identify any of these households. It is clear that the $2 \mathrm{M}$ indicator failed to identify them as energy-poor. Both TPR and HEP calculated with actual energy bills were complementary, with TPR identifying the high actual energy bills and HEP identifying the lower energy bills.

The energy poverty indicators calculated for the city of Évora were also high. There was one household with no heating system, which should be categorized as energy-poor. Once again, 2M did not identify the household with no heating.

In the Basque region, the available data for incomes were more accurate than in the previous two case studies. The indicators took high values for the 1205 households, as low-income households were overrepresented. With regard to the identification of households with no heating, there were different heating systems and different reasons for not having heating; for a multi-occupancy building with individual natural gas boilers, 6 out of 222 dwellings had no gas contract, in the other 4 buildings with prepayment central heating 6 out of the 361 dwellings had zero energy consumption, and for the remaining 8 buildings with central heating (no prepayment) 5 out of 636 dwellings had zero energy expenses. The $2 \mathrm{M}$ was once again the indicator with the poorest ability to identify these households. In contrast, the results of indicators with equivalized modeled bills were relatively accurate.

For future work, given that two of the samples used for this study were from municipalities or regions, it might be interesting to repeat the study in order to extrapolate the results to the rest of the country/ies. Additional socio-demographic variables may also be interesting for analysis, such as long-term illness, disabilities, and hours spent at home. It will be interesting to compare temperature data, to gain insight into indoor thermal comfort levels. The issue of under-consumption is also worth investigating by research groups, i.e., in non-heating energy-uses [14], including effects on people's quality of life.

\section{Conclusions}

In this article the aim was to use an index that considered theoretical energy costs instead of real costs in countries/regions outside the UK. The value of developing a methodology for calculating 
those theoretical energy needs combined with socio-demographic variables is that the problem of targeting households that consume less energy due to restrictions [26] and experience cold at home as a consequence is avoided [18]. The introduction highlighted that, J. Hills also introduced socio-demographic variables in his methodology, known as energy equivalization coefficients, highlighting these as important factors to consider.

In order to calculate those theoretical energy costs, an econometric analysis was carried out. After comparing energy consumption levels in three southern EU region case studies-Greece, city of Évora (Portugal), and the Basque country (Spain)—the effects of certain socio-economic variables were assessed. The results are comparable to those obtained by J. Hills.

These results were applied to the calculation of indexes using modeled energy bills in Portugal, Spain, and Greece. In several countries, energy poverty statistics are assessed using actual bills. Households consuming less than $50 \%$ of theoretical energy needs due to having low incomes are usually not considered as energy-poor according to the TPR using actual expenses. This is a common problem for most European countries. The HEP was developed to identify these households, but when using the median of the actual bills, this index inaccurately captures low energy costs due to high building energy efficiency. This can be avoided using reasonable energy costs, as in Hills [9], or modeled required energy consumption, as in Papada and Kaliampakos [30], the methodology used herein. The conclusion reached for current energy poverty indicators, in line with the opinion of researchers referenced in the introduction such as Moore [18] and Florio and Teissier [26], among others, is that actual expenses is not a good proxy for energy poverty measurement; the fact that under-consuming households and even those with no heating are not considered as energy-poor leads to a targeting problem. Therefore, theoretical energy costs should be used in energy poverty indexes, including in those modeled bills the equivalization factors, as proposed by Hills [9]. This is also effective in inter-country comparison, as theoretical expenses can be excessively high in countries with low mean incomes, such as those in the southern EU regions studied.

Regarding comparison across countries, building an index that does not reflect the impact of energy over time or calculates similar percentages of energy-poor households across countries appears unrealistic. This is the case of indicators based on $2 \mathrm{M}$. A pivotal role should be played by the energy costs-to-income ratio; this means that trade-offs can occur in homes trying to keep their houses warm, e.g., cutting food expenses, or they can fall into debt. This is the so called "heat or eat" dilemma when energy costs in fuel-poor households compete with other basic expenses, which can lead to health consequences [15]. TPR may seem to be arbitrary, setting the amount of energy expenses at $10 \%$, or a normative way of sharing the income among the different expenses. Evaluating energy needs should be performed for the desired outcome, calculating the share of the income destined to energy bills across European countries through the energy costs-to-income ratio approach.

For policymakers, rather than energy prices and energy efficiency, the important variable is energy costs, namely theoretical energy costs. With actual bills, the index does not capture the whole picture. With modeled energy costs, information on both energy efficiency and energy prices is captured: fuel poverty is distinct from income poverty [9], being caused primarily by poor energy efficiency and availability of affordable energy carriers. In the end, the focus should be placed on favoring energy efficiency measures. This also has implications for carbon reduction: in the case of households under-using energy, taking into account only actual bills, investments to reduce carbon emissions cannot be recovered. Other types of benefits-health, employment, indoor air quality, and thermal comfort—should be considered to make those energy efficiency measures 'profitable' [51].

A methodology like this has also implications for future legislation or official standards [6]. The data extracted from HBS are those related to the actual energy bills. If modeled energy bills are to be used, the problem is that the existing building standards for energy efficiency are different across EU countries. The Belgium approach, where the overall heat transfer coefficient of the building envelope (U-value) was advocated by Sunikka-Blank and Galvin [41] for this purpose, this approach is also comparable to the German EPR. However, increasing research on the role of EPCs in energy poverty 
assessment and retrofitting of buildings (e.g., Gouveia and Palma [32] or Charalambides et al. [52]), as well as new ways of accessing European building characteristic data are now available, as the EU Commission launched an initiative to collect data on energy efficiency standards from building stock [53]. The EU SILC data can be used to adjust those socio-economics variables in all EU countries, as well as the Household Budget Survey (HBS).

Author Contributions: Conceptualization, I.A.; methodology, L.P. and I.A.; data access, L.P., J.P.G. and I.A.; writing-original draft preparation, I.A.; writing—review and editing, L.P. and J.P.G.; Short Term Scientific Mission administration, N.K. and D.K. All authors have read and agreed to the published version of the manuscript.

Funding: Iñigo Antepara thanks the ENGAGER Action CA16232 “European Energy Poverty: Agenda Co-Creation and Knowledge Innovation" for the Short Term Scientific Mission scholarship awarded that was completed during March-April 2018 at NTUA, Athens (Greece). João Pedro Gouveia acknowledge and thank the support given to CENSE by the Portuguese Foundation for Science and Technology (FCT) through the strategic project UIDB/04085/2020. The paper stems from collaborative work within COST Action 'European Energy Poverty: Agenda Co-Creation and Knowledge Innovation' (ENGAGER 2017-2021, CA16232) funded by European Cooperation in Science and Technology-www.cost.eu.

Acknowledgments: The authors would like to thank Katherine Mahoney for the English language review. Iñigo Antepara would like to thank Alokabide for allowing access to data.

Conflicts of Interest: The authors declare no conflict of interest.

\section{Appendix A}

Table A1. Correlation analysis for Greek data.

\begin{tabular}{cccc}
\hline Variable & Number of Observations & Spearman's rho & Pearson \\
\hline Actual energy expenses (log) vs occupancy & 400 & $0.2964^{* *}$ & $0.3028^{* *}$ \\
Actual energy expenses (log) vs m ${ }^{*}$ & 400 & $0.4577^{* *}$ & $0.47^{* *}$ \\
\hline Socio-demographic variables & & & \\
\hline Actual energy expenses (log) vs u18 yr. old & 400 & $0.1386^{* *}$ & $0.1381^{* *}$ \\
Actual energy expenses (log) vs Pensioners & 400 & $-0.1554^{* *}$ & $-0.1599^{* *}$ \\
Actual energy expenses (log) vs over 60 & 400 & $-0.0873 \mathrm{~ns}$ & $-0.0822 \mathrm{~ns}$ \\
Actual energy expenses (log) vs Unemployed & 400 & $-0.0866 \mathrm{~ns}$ & $-0.1019^{*}$ \\
\hline
\end{tabular}

* significant at the 0.05 level, ${ }^{* *}$ significant at the 0.01 level, and ns not statistically significant.

Table A2. Correlation analysis for Portuguese data.

\begin{tabular}{|c|c|c|c|}
\hline Variable & Number of Observations & Spearman's rho & Pearson \\
\hline Actual energy expenses (log) vs $\mathrm{m}^{2}$ & 218 & $0.3419 * *$ & $0.2666^{* *}$ \\
\hline Actual energy expenses (log) vs u4 yr. old & 219 & $0.1135 \mathrm{~ns}$ & $0.0686 \mathrm{~ns}$ \\
\hline Actual energy expenses (log) vs u18 yr. old & 219 & $0.2531 * *$ & $0.2323 * *$ \\
\hline Actual energy expenses (log) vs over 65 & 219 & $-0.1749 * *$ & -0.1476 * \\
\hline
\end{tabular}

* significant at the 0.05 level, ${ }^{* *}$ significant at the 0.01 level, and ns not statistically significant.

Table A3. Correlation analysis for Basque data.

\begin{tabular}{|c|c|c|c|}
\hline Variable & Number of Observations & Spearman's rho & Pearson \\
\hline Actual energy expenses (log) vs occupancy & 1216 & $0.1137 * *$ & $0.1097 * *$ \\
\hline Actual energy expenses $(\log ) v^{2} \mathrm{~m}^{2}$ & 1219 & $0.0389 \mathrm{~ns}$ & $0.0454 \mathrm{~ns}$ \\
\hline \multicolumn{4}{|c|}{ Socio-demographic variables } \\
\hline Actual energy expenses (log) vs u4 yr. old & 489 & $-0.1215^{* *}$ & $-0.12 * *$ \\
\hline Actual energy expenses (log) vs u18 yr. old & 489 & $-0.1376^{* *}$ & $-0.1234 * *$ \\
\hline Actual energy expenses (log) vs over 65 & 505 & $-0.0323 \mathrm{~ns}$ & $-0.0629 \mathrm{~ns}$ \\
\hline
\end{tabular}

** significant at the 0.01 level, and ns not statistically significant. 


\section{Appendix B}

Table A4. Equivalization factors proposed by Hills [9].

\begin{tabular}{cc}
\hline Household Type & Equivalization Factor \\
\hline Couple with dependent children & 1.15 \\
Couple without dependent children & 1.00 \\
Lone parent & 0.94 \\
Single person & 0.82 \\
Other multi-person household & 1.07 \\
\hline
\end{tabular}

Table A5. Proposed energy cost equivalization factors by Moore et al. [20].

\begin{tabular}{cccccc}
\hline \multirow{2}{*}{ Household Size } & \multicolumn{5}{c}{ Dwelling Size-Useable Floor Area $\left.\mathbf{( m}^{\mathbf{2}}\right)$} \\
\cline { 2 - 6 } & $<\mathbf{5 0}$ & $\mathbf{5 0 - 6 9}$ & $\mathbf{7 0 - 8 9}$ & $\mathbf{9 0 - 1 0 9}$ & $\mathbf{1 1 0 +}$ \\
\hline Single person & 0.63 & 0.77 & 0.90 & 0.96 & 1.22 \\
Two people & 0.70 & 0.84 & 1.00 & 1.08 & 1.28 \\
Three people & 0.78 & 0.86 & 1.01 & 1.17 & 1.44 \\
Four people & 0.84 & 0.92 & 1.07 & 1.20 & 1.53 \\
Five+ people & 0.87 & 1.00 & 1.14 & 1.31 & 1.62 \\
\hline
\end{tabular}

\section{References}

1. Database-Eurostat. Available online: https://ec.europa.eu/eurostat/data/database (accessed on 29 March 2020).

2. Day, R.; Walker, G.; Simcock, N. Conceptualising energy use and energy poverty using a capabilities framework. Energy Policy 2016, 93, 255-264. [CrossRef]

3. European Commission EU Energy Poverty Observatory 2018. Available online: https://www.energypoverty.eu/ (accessed on 21 June 2020).

4. Gouveia, J.P.; Palma, P.; Simoes, S.G. Energy poverty vulnerability index: A multidimensional tool to identify hotspots for local action. Energy Rep. 2019, 5, 187-201. [CrossRef]

5. Rademaekers, K.; Yearwood, J.; Ferreira, A.; Pye, S.; Hamilton, I.; Agnolucci, P.; Grover, D.; Karásek, J.; Anisimova, N. Selecting Indicators to Measure Energy Poverty; Trinomics: Rotterdam, The Netherlands, 2016.

6. Schuessler, R. Energy Poverty Indicators: Conceptual Issues-Part I: The Ten-Percent-Rule and Double Median/ Mean Indicators; Discussion Paper 14-037; ZEW-Centre for European Economic Research: Mannheim, Germany, 2014.

7. Boardman, B. Fuel Poverty: From Cold Homes to Affordable Warmth; Belhaven Press: London, NY, USA, 1991; ISBN 1-85293-139-6.

8. DECC. Fuel Poverty Methodology Handbook; BRE: London, UK, 2010.

9. Hills, J. Getting the Measure of Fuel Poverty: Final Report of the Fuel Poverty Review; Centre for Analysis of Social Exclusion; The London School of Economics and Political Science; Commissioned by Department of Energy and Climate Change (DECC): London, UK, 2012.

10. Probert, L.; Haines, V.; Loveday, D. The Hills Fuel Poverty Review Interim Report: Assessing Proposals and Implications. People Place Policy Online 2011, 5, 161-173. [CrossRef]

11. Sareen, S.; Thomson, H.; Herrero, S.T.; Gouveia, J.P.; Lippert, I.; Lis, A. European energy poverty metrics: Scales, prospects and limits. Glob. Transit. 2020, 2, 26-36. [CrossRef]

12. Liddell, C.; Morris, C. Fuel poverty and human health: A review of recent evidence. Energy Policy 2010, 38, 2987-2997. [CrossRef]

13. DECC. Fuel Poverty Methodology Handbook; BRE: London, UK, 2016.

14. Simcock, N.; Walker, G.; Day, R. Fuel poverty in the UK: Beyond heating. People Place Policy 2016, 10, $25-41$. [CrossRef]

15. Hills, J. Fuel Poverty: The Problem and Its Measurement. Interim Report of the Fuel Poverty Review; Centre for Analysis of Social Exclusion, LSE: London, UK, 2011. 
16. Hagenaars, A.J.; De Vos, K.; Asghar Zaidi, M. Poverty Statistics in the Late 1980s: Research Based on Micro-Data; Office for Official Publications of the European Communities: Luxembourg, 1994.

17. Bouzarovski, S.; Petrova, S. A global perspective on domestic energy deprivation: Overcoming the energy poverty-fuel poverty binary. Energy Res. Soc. Sci. 2015, 10, 31-40. [CrossRef]

18. Moore, R. Definitions of fuel poverty: Implications for policy. Energy Policy 2012, 49, 19-26. [CrossRef]

19. Heindl, P.; Schuessler, R. Dynamic properties of energy affordability measures. Energy Policy 2015, 86, 123-132. [CrossRef]

20. Moore, R.; Bridgeman, T.; Croft, D.; Guertler, P.; Preston, I. Improving the Hills Approach to Measuring Fuel Poverty; Centre for Sustainable Energy: London, UK, 2012.

21. Imbert, I.; Nogues, P.; Sevenet, M. Same but different: On the applicability of fuel poverty indicators across countries-Insights from France. Energy Res. Soc. Sci. 2016, 15, 75-85. [CrossRef]

22. Healy, J.D. Excess winter mortality in Europe: A cross country analysis identifying key risk factors. J. Epidemiol. Community Health 2003, 57, 784-789. [CrossRef] [PubMed]

23. Bouzarovski, S. ENGAGER Policy Brief 1, COST Action CA16232; University of Manchester: Manchester, UK, 2018.

24. De Ciencias Ambientales, A. Pobreza Energética en España: Hacia un Sistema de Indicadores y una Estrategia de Actuación Estatal [Energy Poverty in Spain: Towards a System of Indicators and a State Action Strategy]; Asociación de Ciencias Ambientales: Madrid, Spain, 2018.

25. EU Energy Poverty Observatory Indicators \& Data. Available online: https://www.energypoverty.eu/ indicators-data (accessed on 6 June 2020).

26. Florio, P.; Teissier, O. Estimation of the Energy Performance Certificate of a housing stock characterised via qualitative variables through a typology-based approach model: A fuel poverty evaluation tool. Energy Build. 2015, 89, 39-48. [CrossRef]

27. Palma, P.; Gouveia, J.P.; Simoes, S.G. Mapping the energy performance gap of dwelling stock at high-resolution scale: Implications for thermal comfort in Portuguese households. Energy Build. 2019, 190, 246-261. [CrossRef]

28. Middlemiss, L. A critical analysis of the new politics of fuel poverty in England. Crit. Soc. Policy 2017, 37, 425-443. [CrossRef]

29. Meyer, S.; Laurence, H.; Bart, D.; Middlemiss, L.; Maréchal, K. Capturing the multifaceted nature of energy poverty: Lessons from Belgium. Energy Res. Soc. Sci. 2018, 40, 273-283. [CrossRef]

30. Papada, L.; Kaliampakos, D. A Stochastic Model for energy poverty analysis. Energy Policy 2018, 116, 153-164. [CrossRef]

31. Papada, L.; Kaliampakos, D. Development of vulnerability index for energy poverty. Energy Build. 2019, 183, 761-771. [CrossRef]

32. Gouveia, J.P.; Palma, P. Harvesting big data from residential building energy performance certificates: Retrofitting and climate change mitigation insights at a regional scale. Environ. Res. Lett. 2019, 14, 095007. [CrossRef]

33. Papada, L.; Kaliampakos, D. Measuring energy poverty in Greece. Energy Policy 2016, 94, 157-165. [CrossRef]

34. Gouveia, J.P.; Seixas, J.; Long, G. Mining households' energy data to disclose fuel poverty: Lessons for Southern Europe. J. Clean. Prod. 2018, 178, 534-550. [CrossRef]

35. European Commission Eurostat. Available online: https://ec.europa.eu/eurostat/ (accessed on 16 November 2019).

36. PORDATA PORDATA—Estatísticas, gráficos e Indicadores de Municípios, Portugal e Europa. Available online: https://www.pordata.pt/ (accessed on 16 November 2019).

37. EUSTAT Datos estadísticos de la C.A. de Euskadi. Available online: http://es.eustat.eus/indice.html (accessed on 17 November 2019).

38. INE Portal do INE. Available online: https://www.ine.pt/xportal/xmain?xpgid=ine_main\&xpid=INE (accessed on 6 June 2020).

39. INE. Instituto Nacional de Estadística. Available online: https://www.ine.es/ (accessed on 6 June 2020).

40. Bair, S.; Belaid, F.; Teissier, O. Quels enseignements tirer de l'enquete Phebus sur la question de l'effet rebond? Les Ménages et La Consomm. d'Énergie 2017, 101-113.

41. Sunikka-Blank, M.; Galvin, R. Introducing the prebound effect: The gap between performance and actual energy consumption. Build. Res. Inf. 2012, 40, 260-273. [CrossRef]

42. INE. Consumo de Energia no Sector Doméstico 2010; INE; DGEG: Lisboa, Portugal, 2011.

43. De Ministerio, V. Código Técnico de la Edificación. Documento Básico HE; Ahorro de energía: Madrid, Spain, 2017. 
44. EVE. Claves energéticas del sector doméstico en Euskadi; Ente Vasco de la Energía: Bilbao, Spain, 2013.

45. University of Oxford Our World in Data 2019. Available online: https://ourworldindata.org/ (accessed on 21 June 2020).

46. Raynaud, M.; Bourges, B.; Osso, D.; Duplessis, B.; Adnot, J. Bottom-up Statistical Analysis of the Energy Consumption of French Single-Family Dwellings; hal-01133743; Archive ouverte HAL: Lyon, France, 2014.

47. Denjean, M. Comportements et consommations énergétiques. Les Ménages et La Consomm. d'Énergie 2017, 60-67.

48. Cavailhès, J.; Joly, D.; Brossard, T.; Cardot, H.; Hilal, M.; Wavresky, P. La Consommation d'Énergie des Ménages en France; INRA/CNRS for the CGDD: Dijon, France, 2011.

49. Risch, A.; Salmon, C. What Matters in Residential Energy Consumption? Evidence from France; hal-01081953; Archive Ouverte HAL: Lyon, France, 2013.

50. Tirado Herrero, S. Energy poverty indicators: A critical review of methods. Indoor Built Environ. 2017, 26, 1018-1031. [CrossRef]

51. Ugarte, S.; van der REE, B.; Voogt, M.; Eichhammer, W.; Ordoñez, J.A.; Reuter, M.; Schlomann, B.; Lloret Gallego, P.; Villafafila Robles, R. Energy Efficiency for Low-Income Households; Policy Department A: Economic and Scientific Policy; European Parliament: Brussels, Belgium, 2016.

52. Charalambides, A.G.; Maxoulis, C.N.; Kyriacou, O.; Blakeley, E.; Frances, L.S. The impact of Energy Performance Certificates on building deep energy renovation targets. Int. J. Sustain. Energy 2019, 38, 1-12. [CrossRef]

53. European Commission EU Building Stock Observatory. Available online: https://ec.europa.eu/energy/topics/ energy-efficiency/energy-efficient-buildings/eu-bso_en (accessed on 3 June 2020).

(C) 2020 by the authors. Licensee MDPI, Basel, Switzerland. This article is an open access article distributed under the terms and conditions of the Creative Commons Attribution (CC BY) license (http://creativecommons.org/licenses/by/4.0/). 